\title{
PIRÂMIDE DE VEGETAÇÃO COMO BASE PARA ESTUDO BIOGEOGRÁFICO NA MICRORREGIÃO DE BOQUIM/SE
}

\author{
Vegetation pyramid as basis for biogeographic study in Boquim / SE Microregion
}

Pirámide de vegetación como base para el estudio biogeográfico en la microrregión Boquim / SE

\author{
Alda Lisboa de Matos Silva ${ }^{1}$ http://orcid.org/0000-0003-1971-1630 \\ Josefa Eliane Santana de Siqueira Pinto ${ }^{2}$ http://orcid.org/0000-0002-1072-1974 \\ Gilmara Silva Freire ${ }^{3}$ http://orcid.org/0000-0001-8374-6876
}

\footnotetext{
${ }^{1}$ Doutora em Geografia - Universidade Federal de Sergipe: - UFS - Brasil - aldinhamatos@ hotmail.com

${ }^{2}$ Doutora em Geografia pela Universidade Estadual Paulista Júlio de Mesquita Filho Professora e Pesquisadora do Programa de Pós-Graduação em Geografia - Universidade Federal de Sergipe: UFS-Brasil, - josefaeliane@ufs.br

${ }^{3}$ Mestranda em Biologia - Universidade Federal de Sergipe: - UFS - Brasil - gilfreire21@ hotmail.com
}

\section{Resumo}

A estruturação do artigo tem como pressuposto a importância da natureza para a sociedade, posto que esta relação tem gerado impactos, descontrole e desequilíbrio. O objeto central considera a análise da vegetação em sua composição da Microrregião de Boquim-SE, considerando as unidades de paisagem, suas características biofísicas, aptidão territorial e manifestações culturais. É parte de uma tese de doutoramento. Por fim considera-se operacional a construção de pirâmides de vegetação, como amostra de análise para avaliar evolução, equilíbrio, progressão e regressão dos estratos em dinâmica com o solo, exposição solo clima, declividade, geologia e ação antrópica. Enfim, base de compreensão da dinâmica ambiental regional.

Palavras-chave: Paisagem. Biogeografia. Dinâmica Socioambiental

\begin{abstract}
The article's structure is based on the importance of nature for society, since this relationship has generated impacts, lack of control and imbalance. The central object considers the analysis of vegetation in its composition in the Boquim - SE Microregion, considering the landscape units, their biophysical characteristics, territorial suitability and cultural manifestations. It is part of a doctoral thesis. Finally, the construction of vegetation pyramids is considered operational, as an analysis sample to evaluate evolution, balance, progression and regression of strata in soil dynamics, soil climate exposure, slope, geology and anthropic action. Finally, the basis for understanding the regional environmental dynamics.
\end{abstract}

Keywords: Landscape. Biogeography. Socioenvironmental Dynamics.

\section{Resumen}

La estructuración de este artículo tiene como presuposición, la importancia de la naturaleza para la sociedad, ya que esta relación ha generado impactos, descontrol y desequilibrio. El objeto central considera el análisis 
de la vegetación, en su composición, de la microrregión de Boquim-SE, considerando las unidades de paisaje, sus características biofísicas, aptitud territorial y manifestaciones culturales y forman parte de una tesis de doctoramiento. Finalmente, se considera operacional la construcción de pirámides de vegetación como muestra de análisis para evaluar la evolución, el equilibrio, la progresión de extractos en dinamismo con el suelo, exposición suelo clima, declividad, geología y acción antrópica. En fin, base de comprensión de dinámica ambiental regional.

Palabras clave: Paisaje. Biogeografía. Dinámica Socioambiental

Recebido em: 30/10/2019

Aceito para publicação em: 01/12/2019

\section{Introdução}

As pirâmides gráficas fazem parte das abordagens de alguns estudos da Geografia, principalmente aqueles relacionados a estrutura e a dinâmica interna da cobertura vegetal. Estar incutido que o estudo vertical da vegetação permite o conhecimento aprofundado das condições biogeográficas e da evolução da vegetação de um lugar. Por meio da avaliação dos parâmetros fitossociológico, é possível perceber o processo evolutivo vegetacional e suas características gerais em seus distintos estratos.

As imagens de satélites apesar de garantir uma boa espacialização, não representam com clareza os estratos e a identificação das espécies, por isso o estudo in sítio é fundamental. O trabalho de campo que esse estudo requer possibilita um leque amplo de formas de representação cartográfica da vegetação, principalmente se acompanhado de técnicas de sensoriamento remoto.

Nesse sentido, o presente artigo apresenta a estrutura vegetacional dos fragmentos florestais da Microrregião de Boquim/ SE, por meio de parâmetros fitossociológicos e de representação cartográfica vertical. Para tanto foram selecionados três pontos (lotes) para realizar a coleta fitossociológica. Essa orientação metodológica de estudo da vegetação permite uma análise integrada dos elementos que compõem a paisagem e possibilita perceber o processo evolutivo da mesma, visto que os fragmentos florestais encontrados na Microrregião de Boquim desde meados de 1964 sofrem pressão socioeconômica, impulsionada pela ampliação das áreas de agricultura e pastagem. 
Vale ressaltar que os dados levantados em campo no desenvolvimento dessa pesquisa fazem parte da tese de doutorado concluída. Nesse estudo, a análise da estrutura da vegetação foi realizada por meio da construção de pirâmides, que é uma metodologia importante de avaliação da vegetação, pois pode representar de forma gráfica a estruturação vertical da formação vegetal de determinado lugar, podendo se estender a uma escala regional.

\section{Pirâmide de vegetação como base para estudo biogeográfico}

Considerando as diferentes concepções geográficas, o estudo da paisagem está associado a imagem formada por um arranjo visível que é tomado pelos sentidos de algum espaço geográfico, relacionado ao meio natural e social, ou seja, a imagem que é produzida pela materialização que cada sujeito observador a ela atribui. As paisagens são as manifestações expressas no espaço tempo das relações sociedade e natureza, que constitui o imaginário, e percebido simultaneamente pelo sujeito. Como afirma Frolova (2006) a concepção de paisagem é abordada de maneira diferente onde:

Os geógrafos da paisagem vão hesitar entre uma abordagem que totaliza, segundo a qual o homem faz parte da paisagem que transforma, e uma abordagem dualista, segundo a qual o homem representa uma força externa à paisagem. Desde a invenção da paisagem científica, as perguntas sobre sua continuidade ou sua descontinuidade e o dualismo ou globalismo da abordagem da paisagem serão tratados de maneiras diferentes (FROLOVA, 2006, p. 163).

O sentido polissêmico do termo paisagem acarreta a existência de uma diversidade de interpretações, consequência da sua formação semântica que assumiu diferentes grafias e significados. Considerar a polissemia no estudo é perceber que qual seja o sistema conceitual empregado não permite compreender a totalidade da interface natureza-sociedade. Dessa forma necessita da construção de um sistema interdisciplinar para unir essa interface. A paisagem enquanto conceito geográfico evoluiu ganhando significações distintas em seu processo histórico. Atualmente o estudo dessa categoria está baseado em duas concepções, uma focada na ótica geossistêmica, fundamentada na abordagem sistêmica, e a outra na ótica cultural, fundamentada pelo método fenomenológico e humanista. 
O estudo da paisagem é entendido por Bertrand (2009), como resultado da combinação dinâmica instável de elementos físico, biológico e antrópico, articulando dialeticamente uns sobre os outros. Segundo Martins (1989) o estudo da vegetação pode revelar mudanças na paisagem, possibilitando a partir do estudo de sua fisionomia e composição florística conhecer o comportamento tempo espacial assim também as características biofísicas.

Existe um consenso sobre a importância da vegetação para a existência de qualquer forma de vida no planeta, por isso ela serve de sensor que adverte possíveis mudanças no ecossistema. Uma das formas de conhecer essas mudanças é por meio de pesquisa fitossociológica, onde se pode conhecer a composição florística e fenológica, a fisiologia e morfologia e outros parâmetros como: abundancia dominância, frequência e sociabilidade. Por meio do estudo dessa composição vegetacional é possível conhecer como se estrutura o clima, o relevo, solo, hidrografia e a interferência antrópica na vegetação.

Segundo Gonçalves et al (2015), o estudo da vegetação é considerado uns dos pilares da pesquisa ambiental, devido sua importância para a qualidade do ambiente e o equilíbrio do sistema natural.

A vegetação atua no processo de regulação dos fluxos do ciclo bioquímico e do balanço energético (entrada e saída de matéria, energia e informação), através da relação de trocas com demais elementos do sistema e da interação com a radiação eletromagnética. (GONÇALVES et al.2015, p, 4702).

\section{Procedimentos para a construção de Pirâmides de Vegetação}

Para elaborar as fichas e as pirâmides de vegetação foi utilizado a metodologia de Bertrand (1966) que se insere na proposta metodológica do sistema GTP (Geossistema- Território-Paisagem). Assim para a representação cartográfica dos estratos vegetais primeiramente foi feito um sensoriamento remoto por meio de imagens de satélite georreferenciadas para analisar a cobertura vegetal como, por exemplo, de fisionomia de Mata Atlântica e, com isto, planejar o estudo de campo.

Após a delimitação das áreas via imagem de satélite Landsat TM foram utilizados quatro critérios para a escolha dos locais de amostragem tais como: relevo e topo, vertente, planície ou fundo de vale - solo, característica da vegetação, no intuito de perceber as descontinuidades fisionômicas e a interferência antrópica. Realizada essa etapa de confirmação das informações digitais no campo e escolhidas os locais de 
amostragem, deu-se sequência com a delimitação das 'áreas core' onde foram realizados os levantamentos fitossociológico.

Após os procedimentos operacionais, foram demarcados três pontos de coleta, e em todas as parcelas, delimitou-se um círculo de 10 metros de raio $\left(314 \mathrm{~m}^{2}\right)$, totalizando $942 \mathrm{~m}^{2}$ de área amostrada. Com a área definida iniciaram-se as anotações no guia de campo que consiste em um modelo de ficha bibliográfica proposto por Bertrand (1966) onde constam de duas partes: na superior, a parte fitossociologica, onde são relacionadas as espécies vegetais mais importantes que ocorrem na formação segundo os estratos ; na inferior, a parte geográfica, onde se detalha os fatores biogeográficos que interferem na formação vegetal, e também a dinâmica de conjunto.

As medidas de altitude, inclinação da vertente e exposição, foram tomadas "in situ" com os aparelhos correspondentes: altímetro, clinômetro, bússola e GPS (sistema de posicionamento global).

Quanto às espécies vegetais, os parâmetros de análises mensurados já são utilizados na ciência Botânica, veemente na Fitossociologia: abundância, dominância e sociabilidade. Os dois primeiros referem-se à equivalência do grau de superfície coberta pelas plantas, escala proposta por Braun-Blanquet (1979), e o ultimo indica o grau de agrupamento das plantas sustentado na proposta de BLANQUET (1979) e BERTRAND (1966).

Além da abundância-dominância e da sociabilidade por espécie vegetal, inserese, na coluna da direita da ficha biogeográfica, a abundância-dominância por estrato, que servirá para a representação na pirâmide de vegetação.

Quadro 1 - Parâmetros fitossociológicos.

\begin{tabular}{|l|l|}
\hline \multicolumn{2}{|c|}{ Percentual de Abundancia/Dominância } \\
\hline & Cobertura entre $75 \%$ à $100 \%$ \\
\hline 4 & Cobertura entre $50 \%$ à $75 \%$ \\
\hline 3 & Cobertura entre $25 \%$ à $50 \%$ \\
\hline 2 & Cobertura entre $10 \%$ à $25 \%$ \\
\hline 1 & $\begin{array}{l}\text { Planta abundante, porém, com valor } \\
\text { de cobertura baixo não superando a } \\
10 \% .\end{array}$ \\
\hline+ & Alguns raros exemplares. \\
\hline
\end{tabular}

\begin{tabular}{|c|l|}
\hline \multicolumn{2}{|l|}{ ercentual de Sociabilidade } \\
\hline 5 & População contínua; manchas densas \\
\hline 4 & $\begin{array}{l}\text { Crescimento em pequenas colônias; } \\
\text { manchas densas pouco extensas. }\end{array}$ \\
\hline 3 & Crescimento em grupos \\
\hline 2 & Agrupadas em 2 ou 3 \\
\hline 1 & Indivíduos isolados \\
\hline+ & Planta rara ou isolada \\
\hline
\end{tabular}

Fonte: Braun-Blanquet, 1979 apud Passos, 2003. 
Após o inventário fotografou-se a área de amostragem. As coletas de material botânico foram realizadas no período de agosto/2017 a outubro/2017. As espécies encontradas foram levadas para o laboratório de Botânica da Universidade Federal de Sergipe onde foram identificadas e catalogadas. Foram coletadas e herborizadas de acordo com a metodologia de MORI et al. (1989). Foi realizada a identificação no herbário ASE com o auxílio de chaves taxonômicas, bibliografia especializada, comparações com exsicatas ${ }^{4}$.

O material foi incorporado ao acervo do Herbário ASE. As famílias foram agrupadas de acordo com o sistema do Angiosperm Phylogeny Group (APG III, 2009) e a confirmação da graia dos nomes científicos foi realizada a partir de consulta no banco de dados da Lista de Espécies da Flora do Brasil (FORZZA et al., 2014). É imprescindível que antes de iniciar o processo biogeográfico, o pesquisador deve detalhar os atributos geográficos, para isso, é necessário um estudo prévio dos fatores do potencial ecológico que insere-se na paisagem, conhecer as características climáticas, os tipos principais de solo e o substrato geológico. Com todo material identificado e catalogado inicia-se a construção da pirâmide de vegetação.

Inicialmente a técnica utilizada foi a manual proposta por Bertrand, (1966) onde sobre um papel milimetrado se constrói um segmento de reta horizontal de $10 \mathrm{~cm}$. de comprimento. Ergue sobre sua base e no centro, perpendicularmente, o eixo da pirâmide, em seguida coloca os estratos de vegetação simetricamente em relação ao eixo, considerando sua ordem normal de superposição, de seu índice de recobrimento (abundância-dominância $1=1 \mathrm{~cm}, 2=2 \mathrm{~cm}, 5=5 \mathrm{~cm}$ ). A espessura de cada estrato, representado na pirâmide, está determinada arbitrariamente, de modo a facilitar as interpretações biogeográficas: estrato $1=0,5 \mathrm{~cm}$, estrato 2 e $3=1 \mathrm{~cm}$, estrato $4=1,5$ $\mathrm{cm}$, estrato $5=2 \mathrm{~cm}$. Posteriormente, foi feito um trabalho gráfico no software Layout 2017 (Trimble) para facilitar a visualização das informações. Além dessas informações colocam-se outras anotações na base da pirâmide como: a espessura, a superfície coberta, o tipo de solo, a rocha mãe, a inclinação, a insolação, e por fim as flechas para indicar a dinâmica dos estratos.

\section{Resultados e discussões}

\footnotetext{
${ }^{4}$ Exsicata é uma amostra de planta prensada e em seguida seca numa estufa (herborizada), fixada em uma cartolina de tamanho padrão acompanhada de uma etiqueta ou rótulo contendo informações sobre o vegetal e o local de coleta, para fins de estudo botânicos e são normalmente guardadas num balão herbário e com auxílio de especialistas em algumas famílias.
} 
O estudo vertical da vegetação permite o conhecimento aprofundado das condições biogeográficas e da evolução da vegetação. As imagens de satélites apesar de garantir uma boa espacialização, não possibilitam com clareza representar os estratos e a identificação das espécies.

Com o propósito de conhecer a estrutura vegetacional dos fragmentos florestais da Microrregião de Boquim foram identificadas as espécies e características gerais em seus distintos estratos. Os dados levantados in sítio como: altura da planta, tamanho da copa, circunferência do caule e também a saúde da planta, classificando-as como saudável, doente ou morta, essenciais para a confecção da ficha biogeográfica. Vale ressaltar que as áreas das referidas coletas não constituem em sua plenitude de floresta nativa, tendo sofrido intenso desmatamento nas décadas de 1960 a 1970, com intuito de formação de assentamentos rurais e lotes agrícolas.

Sociabilidade, Abundância e Dominância estão representadas em forma de Pirâmides de Vegetação nas figuras 1, 2 e 3.

No primeiro ponto de amostragem, a análise dos parâmetros abundância e dominância, proposto por Blanquet (1979) que observa o grau de cobertura vegetal, demonstrou que a formação húmica e a serapilheira recobrem em torno de $75 \%$ a $100 \%$, com grandes quantidades de folhas secas, deixando uma composição pouco inconsolidada.

A área da coleta fitossociológica faz parte do município de Cristinápolis localizado nas coordenadas $11^{\circ} 45^{\prime} 82^{\prime}$ ' S e $37^{\circ} 32^{\prime} 78^{\prime}$ W $\mathrm{W}$ com altitude de $187 \mathrm{~m}$ e está próximo de área de agricultura e pastagem.

A formação vegetal apresenta uma densidade relativa, com alguns trechos de difícil acesso. Quanto a dinâmica dos estratos analisados percebeu-se que o estrato herbáceo quase inexiste, apresentando uma dinâmica regressiva, principalmente pela pouca luminosidade, encontrando apenas alguns raros exemplares. $\mathrm{O}$ estrato subarbustivo encontra-se no nível 2 com cobertura variando entre $25 \%$ a $50 \%$, com destaque a espécie Allophyeys edulis, conhecida popularmente como murta -vermelha ou Murici -brava. O estrato arbustivo encontra-se também em nível 2. O estrato arborescente encontra-se no nível 3 e tem um valor de cobertura entre $25 \%$ a $50 \%$ com destaque a espécie Eugenia hirta. Já o estrato arbóreo encontra-se no nível 5, com cobertura que varia entre $75 \%$ a $100 \%$. Além da Eugenia hirta, a Copteia, Randia e a compomesia aromática esse estrato apresenta alto índice de progressão, chegando a $14 \mathrm{~m}$ 
de altura. Vale ressaltar que o crescimento do estrato arbóreo acarreta a expansão da serapilheira e dos húmus e devido à pouca luminosidade reduz a formação herbácea.

Quanto à sociabilidade, o estrato herbáceo apresenta pequenas manchas. O estrato subarbustivo encontra-se no nível 3 marcado pela presença de pequenos grupos. O estrato arbustivo está no nível 4 apresentando pequenas colônias. O estrato arborescente e o arbóreo estão no nível 1 com altitude entre $8 \mathrm{~m}$ a $14 \mathrm{~m}$ respectivamente.

Infográfico 1 - Pirâmide de Vegetação do lote nº 01no município de Cristinápolis - SE.

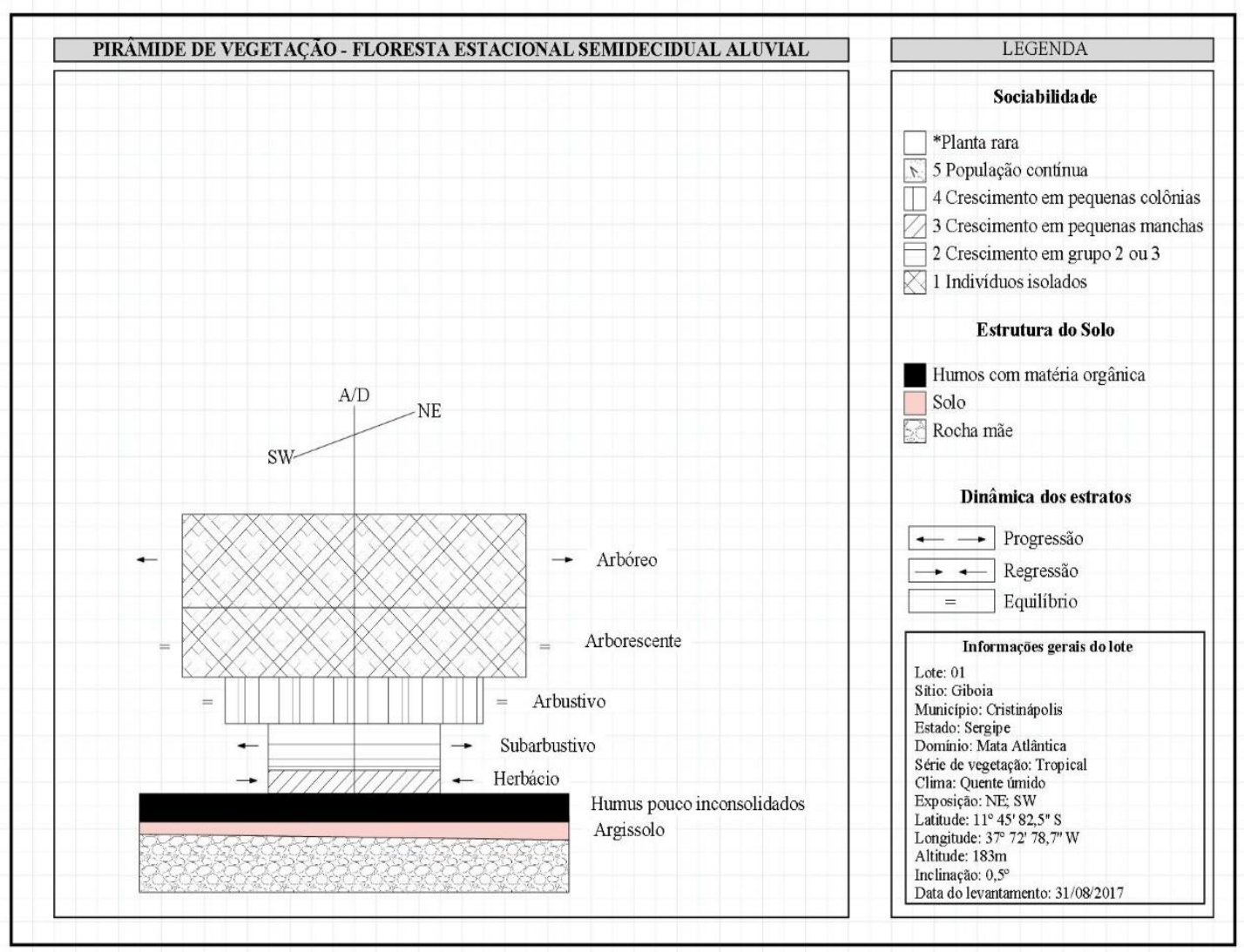

Fonte: SILVA, A.L.M. (2019).

O segundo ponto de amostragem, encontra-se em área de grande pressão antrópica, essa paisagem é marcada pelas pastagens, localizada nas coordenadas $11^{\circ} 16^{\prime} 30^{\prime \prime} \mathrm{S}$ e $37^{\circ} 36^{\prime} 50 \mathrm{~W}$ com altitude de $196 \mathrm{~m}$ no município de Arauá. Nesse trecho a densidade da vegetação por estrato foi bem escasso com exceção do estrato herbáceo característica marcante nesse lote.

O estrato herbáceo nessa unidade amostral encontra-se no nível 5 que equivale a uma cobertura de $75 \%$ a $100 \%$ da área, e nesse lote, destacamos as Sida cuta, Sidastrum multfloutun e a chupheia carthgeneses. O Comportamento do estrato herbáceo pode 
garantir um desenvolvimento do estrato subarbustivo, desde que a atividade pastoril cesse, pois nesse lote o estrato subaburstivo está em nível abaixo de $10 \%$ com alguns raros exemplos de Eugenia herta. Assim não houve formação vegetal arbustiva e arbórea, o maior estrato encontrado foi o arborescente cobrindo cerca de $10 \%$ a $25 \%$ da área com altura média de 8m, marcado pelo Ziziphus joazeiro. Essa área amostral encontra-se em estágio de sucessão secundária, apresentando raros exemplos de alguns remanescentes florestais como Albiziz Polycephala, vetex polygoma e cupania racenosa.

Em relação a sociabilidade, o estrato herbáceo está em nível 5 apresentando uma população continua, o subarbustivo em nível 2 com crescimento em grupo de 2 ou 3 e o estrato e o arborescente em crescimento em pequenas colônias.

Inforgráfico 2 - Pirâmide de Vegetação do lote nº 02 no município de Arauá - SE.

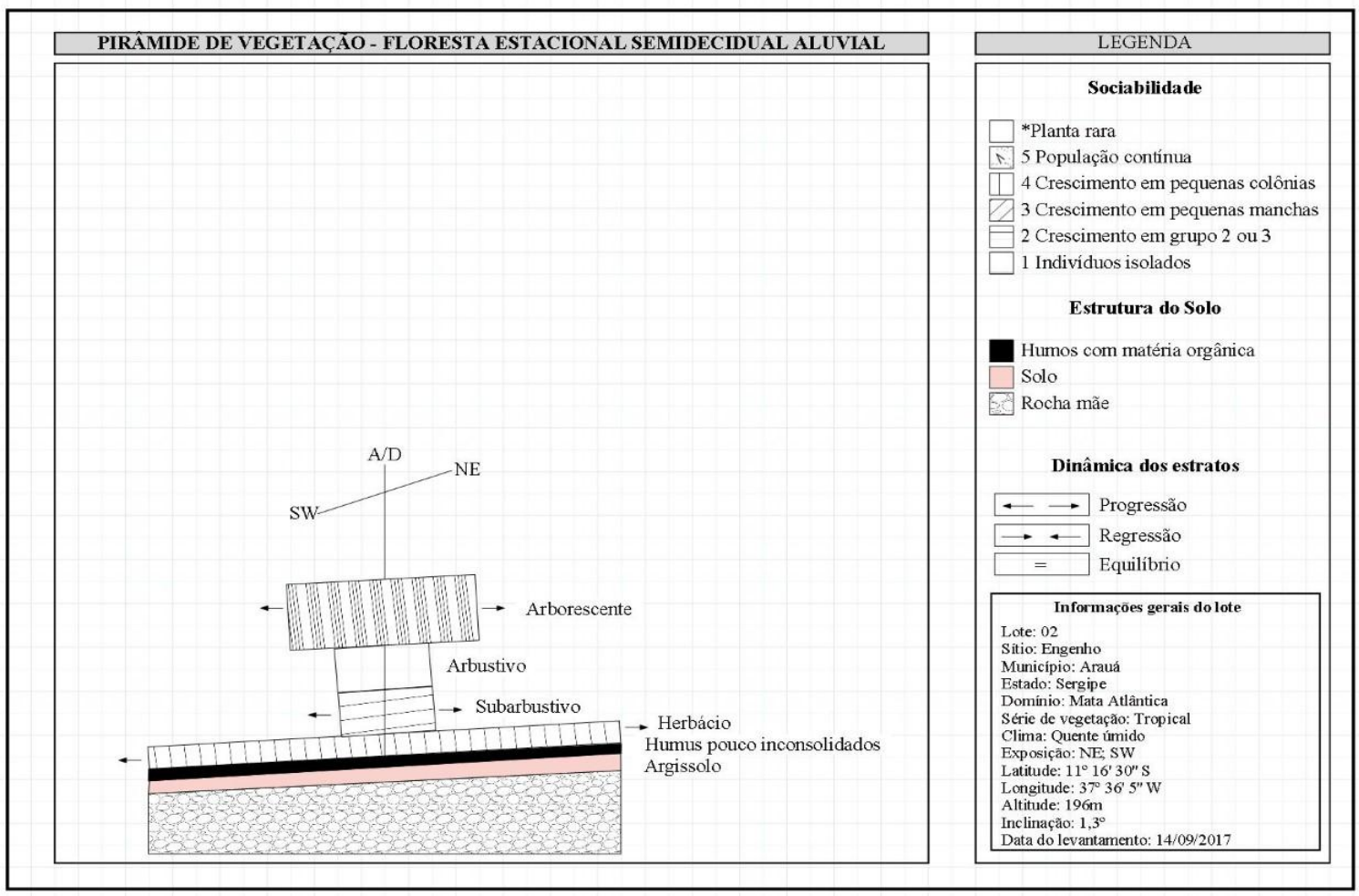

Fonte: SILVA, A.L.M. (2019).

O ponto 3 está situado no município de Umbaúba há 70m do rio Pagão, nas coordenadas $11^{\circ} 23^{\prime} 04^{\prime \prime} \mathrm{S}$ e $37^{\circ} 36^{\prime} 06^{\prime}$ " W, possuindo uma altitude média de $127 \mathrm{~m}$ essa formação ciliar encontra-se em um vale levemente acidentado, marcado em seu entorno pelo desenvolvimento de monocultura da laranja. Apesar da pressão agrícola essa parcela amostral não apresenta erosão aparente ou pontos de desmatamentos. 
Quanto ao grau de abundancia e dominância dessa amostra, notou-se que a formação de serapilheira recobre entre $70 \%$ a $100 \%$ do solo. No estrato herbáceo encontram-se raros exemplares. O estrato subarbustivo está no nível 3, cobrindo entre $25 \%$ a $50 \%$ do solo e o estrato arbustivo no nível 4 cobrindo entre $50 \%$ a $75 \%$ da área. No estrato arborescente observa-se uma formação mais densa, apresentado um grau maior de cobertura. Esse encontra-se no nível 4 também. Já o arbóreo encontra-se no nível 5, apresentando grau de cobertura do solo entre $75 \%$ a $100 \%$. O desenvolvimento do estrato arborescente e arbóreo dificulta a entrada de luz, diminuindo dessa forma o desenvolvimento de algumas espécies principalmente as que fazem parte do estrato herbáceo.

Infográfico 3 - Pirâmide de Vegetação do lote nº 03 no município de Umbaúba - SE

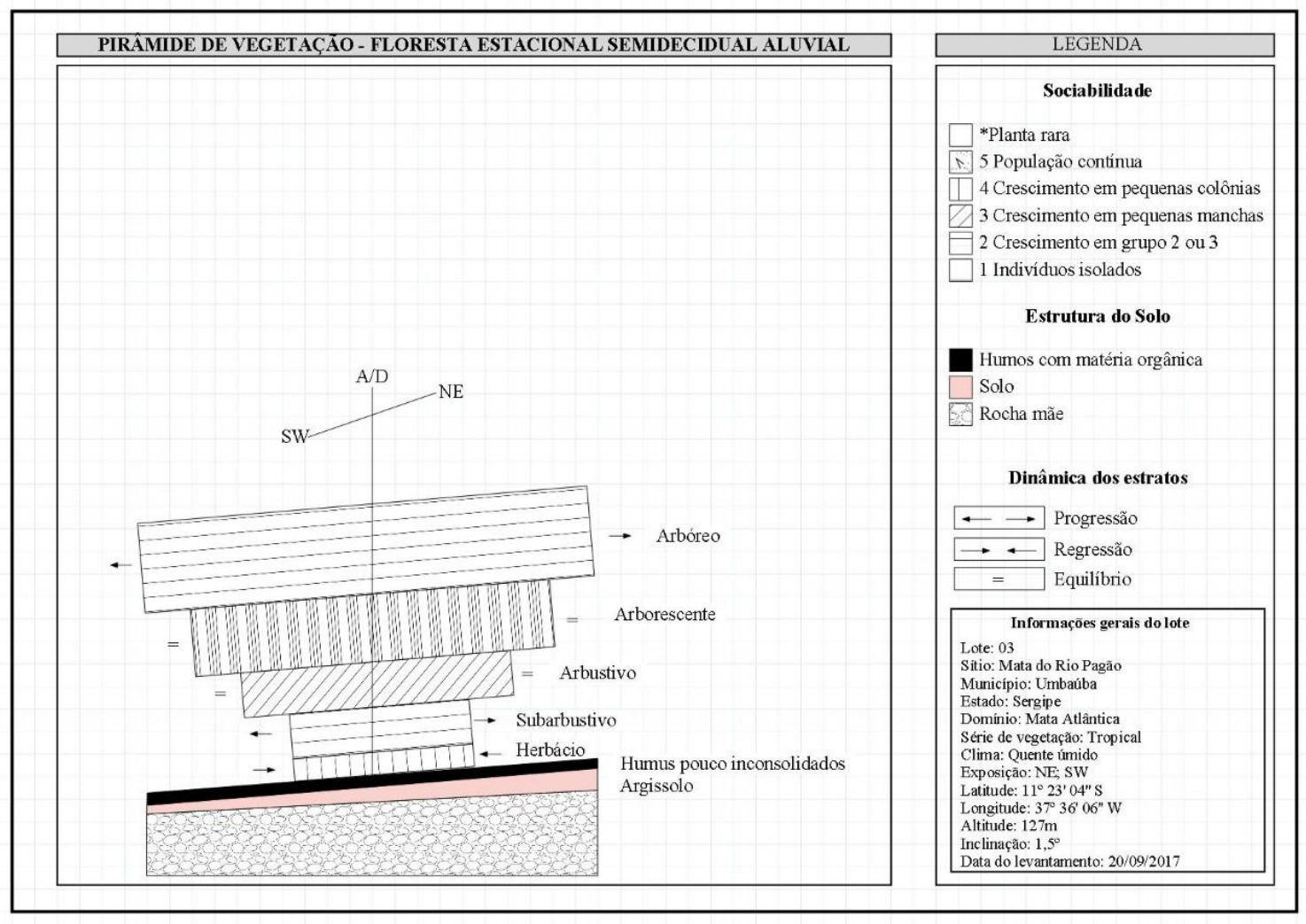

Fonte: SILVA, A.L.M. (2019).

Quanto a sociabilidade o estrato herbáceo apresenta-se com formação de pequenas colônias, já o subarbustivo e o arbóreo encontra-se em formação de grupo de 2 ou 3 espécies e correspondem ao nível 2 de sociabilidade. O estrato arbustivo apresenta-se no nível 5 encontrando manchas de vegetação mais contínua. E o estrato arborescente encontra-se no nível 4 com presença de pequenas colônias. No geral assa 
formação apresenta-se contínua e densa com tendência a uma progressão, com exceção do estrato herbáceo devido à pouca incidência de luminosidade.

\section{Conclusão}

Em amostra recorrente a Mata da Jibóia, em Cristinápolis município da Microrregião, a ação antrópica se faz presente, marcada pela atividade agrícola e criação de gado. Registra-se pequenas trilhas produzidas pela circulação de pessoas, pastoreio de animais e sujeita a contaminação de agrotóxico. Dinâmica de conjunto estável, mas sujeita a degradação.

No sítio Engenho, Arauá, a área é um pequeno lote particular de exploração bovina cercada de arame farpado. Encontram-se grande quantidade de dejetos de gado. Inclinação acentuada do terreno e ameaça de deflorestamento para pasto. Algumas áreas dedicadas as atividades agrícolas e a criação de gado. Em Umbaúba Mata do rio Pagão nota-se baixa pressão antrópica, porém no entorno do lote, encontra-se intensa atividade agrícola de laranja. Apresenta dinâmica estável, vale ressaltar que as atividades agrícolas da-se em pequenas propriedades de ordem familiar. A dinâmica de conjunto desse lote é de progressão positiva. Mesmo em áreas próximas a atividades agrícolas, não houve aumento do desmatamento.

Enfim, o estudo fitossociológico, permite compreender com maior clareza a dinâmica dos geohorizontes, que possibilita avaliar e perceber a evolução, o equilíbrio a progressão e a regressão dos estratos. Esse estudo também auxilia na interpretação da dinâmica de conjunto entre as camadas. Nesse sentido a pirâmide de vegetação tem um papel facilitador, capaz de criar uma representação cartográfica vertical da estrutura vegetal que juntamente com a ficha biogeográfica compõem um produto final, onde expõe a composição dos estratos em sua dinâmica com o solo, a exposição solar, declividade, geologia e ação antrópica.

Associação ao clima foi objeto de análise em outro momento, ainda que haja entendimento de relações ao incluir o estudo no domínio bioclimático.

\section{Referências}

BERTRAND, Claude; BERTRAND, Georges. Uma Geografia transversal e de travessias: o meio ambiente através dos territórios e das temporalidades. Messias Modesto dos Passos (Org.) Maringá. Massoni, 2009. 
BERTRAND G. Pour une étude géographique de lá végetation R.G.P.S. - O. Fasc, 2 ed. p. 129-143,1966.

BRAUN-BLANQUET, J. (1979) - Fitossociologia. Bases para el estudio de las comunidades vegetales. Ed. Blume. Madrid.

FORZZA, R.C., et al. Bromeliaaceae. In: Lista de espécies da Flora do Brasil. Jardim Botânico do Rio de Janeiro, Rio de janeiro, 2014. http//

floradobrasil.jbgj.gov.br/2012/FB000066, (acesso em 01-02-2018).

FROLOVA, Marina; BERTRAND, Georges. Geografía y Paisaje. In: IERNAUX, Daniel; LINDÓN, Alicia (Org.). Tratado de Geografia Humana. Anthropos Editorial. México, 2006.

GONÇALVES, Diogo Laercio, et al. Análise da estrutura vegetal a partir da representação cartográfica com uso de pirâmides de vegetação. XI-ENCONTRO NACIONAL DA ANPEGE. Anais [....] Presidente Prudente/SP. 2015.

http://www.enanpege.ggf.br/2015/anais/arquivos/15/445.pdf. Acesso em 12/04/2018.

MARTINS, F. R. Fitossociologia de Floresta no Brasil um Histórico Bibliográfico. Pesquisas - Série Botânica 40. São Paulo, 1989. MARTINS, S. V. Recuperação de Matas Ciliares. In: Martins, S. V.; Vieira, E. A. (Eds.). Aprenda fácil. Viçosa, 2001.

MORI, S. A. et al. Comparation and structure of an eastern Amazonian forest at Camapi, 1989.

PASSOS, Messias Modesto dos. Biogeografia e Paisagem. 2.ed. Presidente Prudente/SP: PPGE, 2003.

SILVA, Alda Lisboa de Matos. Estruturação socioambiental na microrregião de Boquim/SE Tese (Doutorado em Geografia) São Cristóvão Sergipe 2019. 


\section{Apêndice A}

Ficha biogeográfica

Formação: Floresta Estacional

Domínio Bioclimático: Mata Atlântica Costeira

Semidecidual Aluvial

Unidade Morfoescultural: Tabuleiros dissecados em colinas

Sítio: Mata da Jiboia

Município: Cristinápolis/SE

Declividade: 0,5

Estado: Sergipe
Série de Vegetação: Floresta Tropical

Coordenadas Geográficas:

Latitude: $11^{\circ} 45^{\prime} 82^{\prime} \mathrm{S} \quad$ Longitude: $37^{\circ} 72^{\prime} 78^{\prime}$ W

Exposição: SW/NE Precipitação: $1253 \mathrm{~mm} / \mathrm{ano}$

Data do Levantamento:31/08/2017

\begin{tabular}{|c|c|c|c|c|c|}
\hline \multirow[b]{2}{*}{ Espécies vegetais por Estratos } & \multirow{2}{*}{$\begin{array}{c}\mathrm{N}^{\mathbf{o}} \text { de } \\
\text { indivíduos }\end{array}$} & \multirow{2}{*}{$\begin{array}{c}\text { Altitude } \\
\text { Aprox. } \\
\text { (m) }\end{array}$} & \multicolumn{2}{|c|}{ Espécies: } & \multirow{2}{*}{$\begin{array}{c}\text { Estratos } \\
\text { A/D - } \\
\text { Dinâmica }\end{array}$} \\
\hline & & & $\mathbf{A} / \mathbf{D}$ & $\mathbf{S}$ & \\
\hline \multicolumn{6}{|l|}{ Arbóreo: } \\
\hline Eugenia hirta O. Berg & 6 & 14 & 2 & 1 & \multirow{12}{*}{ Progressão } \\
\hline Rubiaceae sp. & 1 & 10 & 2 & 1 & \\
\hline Cordia sp. & 2 & 11 & 5 & 1 & \\
\hline Lecythis pisonis Cambess & 2 & 12 & 3 & 1 & \\
\hline $\begin{array}{l}\text { Schefflera calva } \\
\text { (Cham.) Frodin \& Fiaschi }\end{array}$ & 3 & 12 & 2 & 1 & \\
\hline Nectandra cuspidata Nees. & 1 & 11 & 1 & 1 & \\
\hline Casearia Jacq. & 4 & 12 & 1 & 1 & \\
\hline Guettarda L. & 4 & 10 & 4 & 2 & \\
\hline Ocotea Aubl. & 21 & 12 & 3 & 1 & \\
\hline Randia L. & 23 & 13 & 4 & 1 & \\
\hline $\begin{array}{l}\text { Campomanesia aromatica } \\
\text { (Aubl.) Griseb }\end{array}$ & 13 & 13 & 4 & 1 & \\
\hline Bauhinia L. & 1 & 12 & 2 & + & \\
\hline \multicolumn{6}{|l|}{ Arborescente } \\
\hline Eugênia hirta O.Berg & 13 & 7 & 3 & 1 & \multirow{6}{*}{ Equilíbrio } \\
\hline $\begin{array}{l}\text { Campomanesia aromatica } \\
\text { (Aubl.) Griseb }\end{array}$ & 2 & 9 & 2 & 1 & \\
\hline Cordia L. & 4 & 6 & 1 & 1 & \\
\hline Randia $\mathrm{L}$. & 7 & 7 & 4 & 2 & \\
\hline $\begin{array}{l}\text { Apuleia leiocarpa } \\
\text { (Vogel) J.F.Macbr. }\end{array}$ & 3 & 8 & 2 & 1 & \\
\hline Schefflera calva & 2 & 7 & 3 & 1 & \\
\hline
\end{tabular}




\begin{tabular}{|c|c|c|c|c|c|}
\hline \multicolumn{5}{|l|}{ (Cham.) Frodin \& Fiaschi } & \\
\hline Annona ambotay Aubl. & 4 & 8 & 1 & 2 & \\
\hline Arbustivo & & & & & \\
\hline Rubiaceae Juss & 1 & 5 & 2 & 1 & \multirow{7}{*}{ Equilíbrio } \\
\hline Cordia sp. & 2 & 4,5 & 1 & 1 & \\
\hline Stropharia alcis var. & 4 & 5 & 3 & 4 & \\
\hline Ocotea Aubl & 6 & 4,5 & 3 & 4 & \\
\hline Randia L. & 1 & 5 & 3 & 1 & \\
\hline Eugênia hirta O. Berg & 8 & 5 & 3 & 4 & \\
\hline Chomélia pubescens Cham \& Schltall. & 3 & 5 & 2 & 2 & \\
\hline \multicolumn{6}{|l|}{ Subarbustiva } \\
\hline Cupania racemosa (Vell.) Radlk. & 6 & 3 & 2 & 3 & \multirow{2}{*}{ Progressão } \\
\hline Allophylus edulis (A.St.-Hil. et al.) & 5 & 2,8 & 2 & 3 & \\
\hline \multicolumn{6}{|l|}{ Herbáceo } \\
\hline cuphea carthagenensis (Jacq.) J. Macbr & $12 \mathrm{em}\left(1 \mathrm{~m}^{2}\right)$ & 0,49 & + & + & \multirow{2}{*}{ Regressão } \\
\hline Sida cordifolia $\mathrm{L}$. & $3 \mathrm{em}\left(1 \mathrm{~m}^{2}\right)$ & 0,38 & + & + & \\
\hline
\end{tabular}

Humos/ serrapilheira: Presença de raízes finas, folhagem e galhos secos e em decomposição.

Clima: Tropical litorâneo

Microclima: Clima quente e úmido com bastante sombra

Rocha mãe: Embasamento gnáissico do Arqueano Paleoproterozóico

Solo: Argissolo 


\section{Apêndice B}

Ficha biogeográfica

Formação: Floresta Estacional

Domínio Bioclimático: Mata Atlântica

Semidecidual

Unidade Morfoescultural: Tabuleiros dissecados em colinas

Sítio: Sítio Engenho

Município: Arauá/SE

Estado: Sergipe
Série de Vegetação: Floresta Tropical

Coordenadas Geográficas:

Latitude: $11^{\circ} 16^{\prime} 30^{\prime \prime} \mathrm{S}$

Longitude: $37^{\circ} 36^{\prime} 50^{\prime \prime} \mathrm{W}$

Exposição: NNE

Precipitação: 863,3 mm/ano

Data do Levantamento: 14/09/2017

\begin{tabular}{|c|c|c|c|c|c|}
\hline \multirow{2}{*}{ Espécies vegetais por Estratos } & \multirow{2}{*}{$\begin{array}{c}\mathbf{N}^{\mathbf{o}} \text { de } \\
\text { indivíduos }\end{array}$} & \multirow{2}{*}{$\begin{array}{c}\text { Altitude } \\
\text { Aprox. } \\
\text { (m) }\end{array}$} & \multicolumn{2}{|c|}{ Espécies: } & \multirow{2}{*}{$\begin{array}{c}\text { Estratos } \\
\text { A/D - } \\
\text { Dinâmica }\end{array}$} \\
\hline & & & $\mathbf{A} / \mathbf{D}$ & $\mathbf{S}$ & \\
\hline \multicolumn{6}{|l|}{ Arbóreo: } \\
\hline \multicolumn{6}{|l|}{ Arborescente } \\
\hline Ziziphus Mill & 15 & 6 & 3 & 2 & \multirow{4}{*}{ Progressão } \\
\hline Albizia Durazz. & 2 & 7 & 1 & 1 & \\
\hline Polygonum L. & 1 & 8 & 1 & + & \\
\hline Cupania racemosa (Vell.) adlk. & 2 & 6 & 1 & 1 & \\
\hline \multicolumn{6}{|l|}{ Arbustivo } \\
\hline \multicolumn{6}{|l|}{ Subarbustiva } \\
\hline Eugenia hirta O.Berg & 8 & 4 & + & 2 & Regressão \\
\hline \multicolumn{6}{|l|}{ Herbáceo } \\
\hline Sida cordifolia $\mathrm{L}$. & $25 \mathrm{em}\left(1 \mathrm{~m}^{2}\right)$ & 0,45 & 3 & 5 & \multirow{7}{*}{ Progressão } \\
\hline Sidastrum multiflorum (Jacq.) Fryxell & $21 \mathrm{em}\left(1 \mathrm{~m}^{2}\right)$ & 0,52 & 4 & 5 & \\
\hline Cuphea carthagenensis (Jacq.) J.Macbr & $41 \mathrm{em}\left(1 \mathrm{~m}^{2}\right)$ & 0,54 & 5 & 5 & \\
\hline Ruellia bahiensis (Nees) Morong & $1 \mathrm{em}\left(1 \mathrm{~m}^{2}\right)$ & 0,35 & 2 & 1 & \\
\hline Rubiaceae Juss & $1 \mathrm{em}\left(1 \mathrm{~m}^{2}\right)$ & 0,52 & 2 & 1 & \\
\hline Asteracea & $2 \mathrm{em}\left(1 \mathrm{~m}^{2}\right)$ & 0,27 & 2 & 1 & \\
\hline Stemodia foliosa Benth. & $4 \mathrm{em}\left(1 \mathrm{~m}^{2}\right)$ & 0,25 & 3 & 2 & \\
\hline
\end{tabular}

Humos/ serrapilheira: presença de raízes finas, folhagem e galhos secos e em decomposição.

Clima: Tropical litorâneo

Microclima: Clima quente e úmido com bastante sombra

Rocha mãe: Embasamento gnáissico do Arqueano Paleoproterozóico

Solo: Argissolo 


\section{Apêndice C}

\begin{tabular}{lcc}
\hline & Ficha biogeográfica & Parcela n $^{\mathbf{0} 03}$ \\
\hline Formação: Floresta Estacional & Domínio Bioclimático: Mata Atlântica & \\
Semidecidual & &
\end{tabular}

Unidade Morfoescultural: Tabuleiros dissecados em colinas

Sítio: Mata do Rio Pagão

Município: Umbaúba/SE

Altitude: 127

Declividade: 1,5

Estado: Sergipe
Série de Vegetação: Floresta Tropical

Coordenadas Geográficas:

Latitude: $11^{\circ} 23^{\prime} 04^{\prime \prime} \mathrm{S} \quad$ Longitude: $37^{\circ} 36^{\prime} 06^{\prime \prime} \mathrm{W}$

Exposição: SW/NE Precipitação: $1291 \mathrm{~mm} / \mathrm{ano}$

Data do Levantamento: 20/09/2017

\begin{tabular}{|c|c|c|c|c|c|}
\hline \multirow[b]{2}{*}{ Espécies vegetais por Estratos } & \multirow{2}{*}{$\begin{array}{c}\mathrm{N}^{\mathrm{o}} \text { de } \\
\text { indivíduos }\end{array}$} & \multirow{2}{*}{$\begin{array}{l}\text { Altitude } \\
\text { Aprox. } \\
\text { (m) }\end{array}$} & \multicolumn{2}{|c|}{ Espécies: } & \multirow{2}{*}{$\begin{array}{c}\text { Estratos } \\
\text { A/D - } \\
\text { Dinâmica }\end{array}$} \\
\hline & & & $\mathbf{A} / \mathbf{D}$ & $\mathbf{S}$ & \\
\hline \multicolumn{6}{|l|}{ Arbóreo: } \\
\hline Lonchocarpus Kunth & 3 & 14 & 5 & 2 & \multirow{8}{*}{ Progressão } \\
\hline $\begin{array}{l}\text { Eschweilera ovata (Cambess.) Mart. ex } \\
\text { Miers }\end{array}$ & 10 & 10 & 3 & 2 & \\
\hline Cupania racemosa (Vell.) Radlk. & 2 & 9 & 2 & 2 & \\
\hline Guazuma ulmifolia Lam & 2 & 9 & 3 & 2 & \\
\hline Cecropia pachystachya Trécul & 4 & 12 & + & 1 & \\
\hline Fabaceae Lindl & 2 & 10 & 1 & 1 & \\
\hline Tapirira guianensis Aubl. & 9 & 14 & 1 & 2 & \\
\hline Inga vera Willd. & 3 & 10 & 3 & 5 & \\
\hline \multicolumn{6}{|l|}{ Arborescente } \\
\hline Cupania impressinervia Acev.-Rodr. & 7 & 9 & 3 & 4 & \multirow{9}{*}{ Equilíbrio } \\
\hline Cordia sellowiana Cham. & 1 & 8 & 1 & 1 & \\
\hline $\begin{array}{l}\text { Lonchocarpus sericeus (Poir.) Kunth ex } \\
\text { DC. }\end{array}$ & 6 & 7,5 & 5 & 4 & \\
\hline Mytenus & 11 & 7,5 & 5 & 5 & \\
\hline Cupania racemosa (Vell.) Radlk. & 2 & 6 & 2 & 1 & \\
\hline Ocotea gardneri Meisn. & 8 & 8 & 5 & 5 & \\
\hline Guazuma ulmifolia Lam & 6 & 6 & 3 & 4 & \\
\hline Alseis pickllei Plig. \& Schmale & 2 & 6,5 & 2 & 2 & \\
\hline Swartzia apetala Raddi. var & 5 & 6 & 1 & 2 & \\
\hline \multicolumn{6}{|l|}{ Arbustivo } \\
\hline Cupania impressinervia Acev.-Rodr. & 5 & 5 & 3 & 4 & Equilíbrio \\
\hline Cordia sellowiana Cham. & 2 & 5 & 1 & 1 & \\
\hline Guettarda viburnoides & 2 & 5 & 2 & 1 & \\
\hline
\end{tabular}




\begin{tabular}{|c|c|c|c|c|c|}
\hline Cupania racemosa (Vell.) Radlk & 1 & 5 & 2 & 1 & \\
\hline Dialium L. & 6 & 5 & 1 & 3 & \\
\hline Myrcia sylvatica (G.Mey.) DC & 1 & 5 & 2 & 1 & \\
\hline Ocotea Gardneri Meisn. & 9 & 5 & 4 & 4 & \\
\hline \multicolumn{6}{|l|}{ Subarbustiva } \\
\hline Alseis pickllei Plig. \& Schmale & 4 & 3 & 2 & 3 & Progressão \\
\hline $\begin{array}{l}\text { Lonchocarpus sericeus (Poir.) Kunth ex } \\
\text { DC. }\end{array}$ & 5 & 4 & & 3 & \\
\hline $\begin{array}{l}\text { Eschweilera ovata (Cambess.) Mart. ex } \\
\text { Miers }\end{array}$ & 7 & 3 & 3 & 4 & \\
\hline Cupania impressinervia Acev.-Rodr. & 5 & 4,5 & 3 & 3 & \\
\hline Cordia sellowiana & 4 & 3,5 & 1 & 1 & \\
\hline Cupania racemosa (Vell.) Radlk. & 2 & 4,5 & 1 & 1 & \\
\hline Byrsonima sericea DC & 1 & 2,5 & + & + & \\
\hline Coccoloba paraensis Meisn & 9 & 3 & 3 & 5 & \\
\hline Dialium L. & 4 & 4 & 1 & 2 & \\
\hline Tapirira guianensis Aubl. & 1 & 3 & 1 & 3 & \\
\hline Hirtella racemosa Lam & 1 & 3 & + & + & \\
\hline Myrcia sylvatica (G.Mey.) DC & 2 & 4 & 2 & 1 & \\
\hline Swartzia apetala Raddi. Var & 1 & 3 & 1 & + & \\
\hline Campomanesia dichotoma (O.Berg) Mattos & 7 & 4,5 & 1 & 1 & \\
\hline $\begin{array}{l}\text { Campomanesia aromatica } \\
\text { (Aubl.) Griseb }\end{array}$ & 4 & 3,5 & 2 & 1 & \\
\hline \multicolumn{6}{|l|}{ Herbáceo } \\
\hline Ruellia bahiensis (Nees) Morong & $3 \mathrm{em}\left(1 \mathrm{~m}^{2}\right)$ & 0,30 & 1 & + & Regressão \\
\hline Rubiaceae Juss. & $4 \mathrm{em}\left(1 \mathrm{~m}^{2}\right)$ & 0,56 & 1 & + & \\
\hline
\end{tabular}

Humus/ serapilheira: folhagem e matéria orgânica vegetal secos e em decomposição.

Clima: Tropical litorâneo

Microclima: Clima quente e úmido com bastante sombra

Rocha mãe: Embasamento gnáissico do Arqueano Paleoproterozóico

Solo: Argissolo 